https://doi.org/10.31713/m1110

\title{
PROSPECTS FOR SURFACE MINING OF IRON ORE DEPOSITS IN UKRAINE
}

\author{
Slobodyanyuk V.K. \\ The National University of Kryvyi Rih, PhD (Engineering), \\ Associate Professor, the Department of Open Pit Mining Operations, \\ Ukraine
}

\begin{abstract}
At present, new iron ore deposits with much more favorable mining and geological conditions than in Ukraine are being commissioned abroad. Factors that currently complicate the operation of iron ore pits in Ukraine are the significant amount of stripping operations and the need to alienate large areas of agricultural land to place waste dumps.

The purpose of this study was to determine the parameters of the most typical iron ore deposits, surface mining of which is possible in the future. The geometric dimensions and depositional conditions of iron ore deposits largely determine the main parameters of the open pit, its production capacity, development system, the method of opening-up and the key performance indicators.

It was found that the stratified deposits are $82.5 \%$ of reserves of ferruginous quartzite and $83.3 \%$ of the total number of deposits, synclinal deposits $-3.3 \%$ of reserves and $8.3 \%$ of deposits, anticlinal - about $14 \%$ of the balance reserves and $8.3 \%$ of the number of deposits. $50 \%$ of ferruginous quartzite reserves are represented by deposits with a horizontal thickness of over $200 \mathrm{~m}$.

The performed mining and geometric analysis of iron ore deposits is the basis for the development of new surface mining technologies, which will ensure the costefficient development of ferruginous quartzite deposits with complex mining and geological conditions.
\end{abstract}

\section{Introduction}

\section{A track record in systematization of iron ore deposits and ge- ometric analysis of open pit fields in iron ore open pit mines.}

It is known that the geometrical dimensions and conditions of occurrence of iron ore deposits largely predetermine the main parameters of the open pit, its production capacity, the development system, the method of opening-up and the key performance indicators.

In the surface mining theory, there are several examples of systematization of iron ore deposits according to mining and geological conditions in order to determine common approaches to the development [1-5].

Depending on the mining and technical conditions of iron ore de- 
posits in Ukraine, it was proposed [5] to identify six typical open pits with a surface length of one to six kilometers and a width of 300 to $800 \mathrm{~m}$ (Table 1). In [5], in reliance on the proposed classification of typical deposits, the potential of the raw material base of Ukrainian mining and processing companies (GOKs) were studied.

Open pits of the first, third and sixth types have a rounded shape and develop synclinal deposits, open pits of the second, fourth and fifth types develop steeply dipping stratified deposits. The output capacities of typical open pits are determined depending on the area of ore bodies. The open pits of the $1^{\text {st }}$ type include Pit No. 1 of AMKR, Pits No. 2 and No. 4 of Central GOK. Type 2 is represented by Pit No. 2 of AMKR, pits of InGOK, Mikhailovsky and Lebedinsky GOKs. Pit No. 3 of AMKR, the pit of YuGOK, Pervomaisky pit of SevGOK, Pit No. 3 of Central GOK are included in type 3. Pit No. 1 of Central GOK, Stoilensky and Sokolovsky pits of SSGOK belong to the $4^{\text {th }}$ type. The pit of Poltavsky GOK, Annovsky pit of SevGOK and Sarbaisky pit of SSGOK are characteristic for type 5. The $6^{\text {th }}$ type is the United pit of YuGOK and Pit No.3 of AMKR (promising open pit).

Table 1

Key parameters of typical iron ore open pits [5]

\begin{tabular}{|c|c|c|c|c|c|c|}
\hline \multirow{2}{*}{ Indicator } & \multicolumn{6}{|c|}{ Type of an open pit field } \\
\hline & 1 & 2 & 3 & 4 & 5 & 6 \\
\hline imensions c & & & & & & \\
\hline - horizontal thi & 370 & 300 & 875 & 300 & 350 & 1300 \\
\hline - mining depth & 300 & 400 & 500 & 500 & 600 & 800 \\
\hline - length on the lev & & & & & & \\
\hline mate mining depth & 150 & 900 & 1600 & 2680 & 4350 & 3800 \\
\hline Dimensions of a pit field, $\mathrm{m}$ : & & & & & & \\
\hline - surface length & 1000 & 2000 & 3000 & 4000 & 5000 & 6000 \\
\hline - surface w & 1000 & 1200 & 2000 & 1200 & 2500 & 3000 \\
\hline - are & 82.6 & 194.6 & 487.2 & 476.2 & 826.3 & 1509 \\
\hline Rock volume in the pit, mln $n$ & & & & & & \\
\hline - rock mass & 108.5 & 374.7 & 1392.7 & 1192.5 & 2730 & 7139 \\
\hline - iro & 58.2 & 152.9 & 890.9 & 451.7 & 1013.6 & 4573 \\
\hline - overburc & 50.3 & 221.8 & 501.8 & 740.8 & 1716.4 & 2565 \\
\hline$-a$ & 90.6 & 399.2 & 903.2 & 1333.5 & 3089.5 & 4617 \\
\hline Avera & 0.86 & 1.45 & 0.56 & 1.64 & 1.69 & 0.56 \\
\hline Total area under mining, ha & 312.8 & 960.6 & 3528.4 & 2893.7 & 6348.6 & 17101.2 \\
\hline Annual output ca & & & & & & \\
\hline & 2.6 & 4.0 & 6.8 & 6.0 & 9.0 & 12.4 \\
\hline - overburden & 2.2 & 5.8 & 3.8 & 9.84 & 15.2 & 6.95 \\
\hline
\end{tabular}


This approach to the classification of iron ore deposits and open pits has a number of disadvantages.

Firstly, the typical open pits reflect the mining and geological conditions of the best Ukrainian open pits. Currently, most of the unique and large iron ore deposits and several medium-sized deposits are involved in development. Such favorable conditions for surface mining will not be repeated in the future. Deposits with difficult mining and geological conditions will be involved in development. At the same time, the sixth type of open pit is designed to simulate the development of a unique synclinal deposit with favorable mining and geological conditions.

Secondly, the proposed classification does not provide for open pits that develop anticlinal deposits. A number of operating and projected iron ore open pits develop anticlinal deposits.

Thirdly, the classification does not give an answer as to how the proposed open pits and deposits are typical for the conditions of Ukraine. Knowing what types of deposits and geological environment will prevail in the future will allow giving a long-term outlook to the importance of the iron ore industry for the Ukrainian economy and directions of development of theory and practice of surface mining of iron ore deposits.

The main provisions of classification, typification and parameterization of iron ore deposits

The need to group iron ore deposits is extremely relevant, since it allows identifying the types of deposits with similar features. However, the approaches to different types of classifications may vary from the point of view of different specialists. As noted by G.A.Gross, "one of the difficulties in creating such a classification is the difference in the interests of an exploration geologist, mining engineer, metallurgist and economist. A single classification is not able to satisfy all these interests." [6]. And yet, iron ore deposits of one or several formations in terms of genesis have many similarities, among which we can highlight the most important in the context of surface mining operations.

The most general classification is based on geological and genetic criteria. Relying on geotectonic and metallogenic zoning within the Ukrainian Shield, five large iron-bearing zones have been identified: Odessko-Belotserkovskaya;

Krivorozhsko-Kremenchugskaya; 
Pridneprovskaya; Belozersko-Orekhovskaya; Priazovskaya.

Another most important parameter is the value of indicated reserves of iron ore in the subsurface. The classification given in [7], with some alterations, may be considered the most optimum. It was calculated taking into account the statistical distribution of occurring natural types of iron ore deposits over a larger area of the ex-USSR (Table 2).

According to their industrial importance, mineral reserves are divided into balance and off-balance reserves. The balance reserves meet the specifications for calculation of reserves in the subsurface and their use is currently economically viable. The off-balance reserves are reserves that are currently economically inexpedient to exploit due to their small number, small deposit size, low content and special complexity of operating conditions, and the need to apply complex processing, but which may become the subject of industrial development in the future.

Table 2

Classification of the USSR iron ore mineral resource base by deposit size [7]

\begin{tabular}{l|c|c|l|l}
\hline Deposit size & $\begin{array}{l}\text { Number of } \\
\text { deposits, \% }\end{array}$ & $\begin{array}{l}\text { Metal reserves, } \\
\text { mln tons }\end{array}$ & $\begin{array}{l}\text { Percentage of } \\
\text { metal in re- } \\
\text { serves, \% as of } \\
1986\end{array}$ & $\begin{array}{l}\text { Percentage of } \\
\text { metal in ore } \\
\text { mined, \% as of } \\
1986\end{array}$ \\
\hline Unique & 1.5 & $>3000$ & 32 & 6 \\
\hline Rather large & 1.5 & $1500-3000$ & 13 & 20 \\
\hline Large & 10 & $350-1500$ & 36 & 47 \\
\hline Medium & 27 & $50-350$ & 15 & 21 \\
\hline Small & 37 & $5-50$ & 3.8 & 5.2 \\
\hline Ore occurrence & 23 & $<5$ & 0.2 & 0.8 \\
\hline
\end{tabular}

Each ore deposit is characterized by a peculiar, unique structure. However, there are some groups of deposits, united by a common genesis, with similar structure-forming conditions, which show very similar structural features. The greatest degree of similarity is found in the iron ore deposits composed of ferruginous quartzite: both large basins, such as Krivorozhsky and Kremenchugsky, as well as individual deposits.

When dividing deposits into categories and types, the basis was those features of the structure that significantly affect its development, namely the structure of the productive stratum and its main parameters. In addition, the structure of the host rocks to be excavat- 
ed on the way was taken into account.

Attempts to systematize the ore-bearing structures were made long ago. Here we should note the work entitled "Structure of Ore Fields of Krivorozhsky Iron Ore Deposits" by N.P. Semenenko (1946). It extensively provides both data on the ore-bearing structures of rich iron ores and data on the tectonics of iron ore strata. Numerous works by E.N. Belevtsev (1946, 1952, 1955, 1957, 1962, 1989), G.V. Tokhtuev (1955, 1989), D.I. Ischenko (1955), A.P. Karshenbaum (1959), V.P. Maksimovich (1955), M.I. Chernovsky $(1962,1989)$ have been devoted to tectonics and structural analysis of iron ore strata, and a series of monographs - "Iron Ore Formations of Pre-Cambrian".

The types of ferruginous quartzite deposits in the Krivoy Rog region was systematized by A.V. Plotnikov and M.I. Chernovsky [8]. They identify the structural types of deposits as follows: monoclinal, flexural, synclinal, anticlinal and blocky. It should be noted that the authors based the division of the selected types on the different types of large folds (synclines, anticlines, flexures) or their fragments monoclines, as well as deposits with a predominantly block structure.

If we consider the systematization of ferruginous quartzite deposits more broadly, taking into account other ore provinces, it is worth noting that both folded deformations and discontinuous ones that break the ore sequence into differently-sized blocks are widely represented in any deposit of the Precambrian ferruginous-siliceous formation. Therefore, almost every deposit is characterized by a foldblock structure. The question rests on the size of geological formations and their consistency within the area of proposed mining. In view of this, while systemizing one may emphasize those basic features of structural iron ore deposits, which play a decisive role in the development of the deposit.

Considering the above and the previous track record in systematization of iron ore deposits, it is proposed to divide their structures into two large categories such as predominantly folded and blocky. In the category of folded deposits, folded deformations play the main role, with a relatively small degree of block influence. The category of block deposits, in turn, is characterized by the development of block structures, and the role of folds is relatively minor.

The main structural types of Precambrian iron ore deposits 


\section{in Ukraine}

The category of folded depositsDeposits in the closures of large synclines (Skelevatsky type)

This type of deposits is characterized by the largest reserves of iron ore, large size, favorable mining conditions and high ore output capacity of open pits.

The synclinal folds are entirely composed by iron-bearing sequence. Productive levels are interspersed partially with nonproductive ones. These deposits are very convenient for large open pits. The dip of rocks in the pit walls $\left(50-70^{\circ}\right)$ coincides with the slopes of non-mining pit walls ensuring their sufficient stability in case of significant deepening. The large size of open pits creates normal conditions to locate transport communications on their walls.

The peculiarity of the geological structure of these deposits is their location in the area of the southern centriclinal closure of large linearly elongated synclinal folds.

Among these deposits we can distinguish several groups, differing by certain features of the structure and size.

Deposits of the first group are located in folds with a gentle plunge of the hinge. These deposits include the Skelevatskoye Magnetite deposit, which is located in the central part of ZapadnoInguletskaya syncline of the Krivbass, and the Belanovskoye deposit, located within the closure of Galeshchinskaya syncline in the Kremenchugsky basin.

Deposits of the second group are located in the cup-shaped closures. The deposit proper encompasses this entire structure, which expands in the area of closing, and the structure becomes dropshaped in plan. The Inguletskoye and Gorishne-Plavninskoye deposits belong to this group.

A somewhat special position is held by the group of Zheltorechenskiye deposits, the structure of which differs from the first two groups by many structural features.

The first group of deposits represents the most well-studied Skelevatskoye Magnetite deposit, which has been in operation since 1955. The peculiarity of its structure is a very gentle plunge of the hinge from south to north. Within the deposit, an angle of plunge averages $15^{\circ}$. This hinge position contributes to an increase in the 
horizontal thickness of the most productive levels, especially in the area of the centroclinal closure, despite complications caused by discontinuous tectonic faults. The greatest depth of plunging the IV main productive ferruginous level is about $800 \mathrm{~m}$ in the northern part of the deposit. Further north, the ore body is overlain by oxidized quartzite of the fifth and sixth ferruginous levels.

\section{Deposits in the closure of relatively small faulted synclines.}

A subtype of Skelevatsky type of iron ore deposits are smaller iron ore deposits of the synclinal type (Petrovskoye, Artemovskoye, Proletarskoye and others).

Deposits of Petrovsky subtype are located within narrow, appressed synclinal ore fields or represented by their fragments. In contrast to the basic type, these deposits are characterized by a much greater diversity.

Along with appressed and subparallel limbs of synclinal folds (Petrovskoye deposit), among these deposits, there are centroclinal closures with diverging limbs (Artemovskoye and Proletarskoye deposits). The hinges of synclinal folds slope both to the north and to the south (Artemovskoye deposit).

The peculiarities of deposits of this subtype are numerous discontinuous tectonic faults, often dividing the ore body into separate, different in size geological blocks.

The Artemovskoye deposit is located within the synclinal fold of the same name (Skelevatsky type). The surface length of the fold is about $3 \mathrm{~km}$, and the wavelength of limbs in the southern part is up to $1 \mathrm{~km}$. The fold has undergone complex deformations. Its closure faces to the north and opens to the south. The entire fold is complicated by discontinuities. The axis of the fold in the area of closing has a submeridional strike, then, in the middle part, it acquires a southeastern direction SE $155-160^{\circ}$, and in the southernmost part it again takes a submeridional orientation SE $175-178^{\circ}$, NS $0-180^{\circ}$. The extension of the axial plane is also characterized accordingly. Its dip from north to south also changes. In the northern and southern parts it is subvertical, in the central part - steep western. The hinge of the fold plunges southward at angles of $20-30^{\circ}$ (average $25^{\circ}$ ), causing the closure to plunge southward to depths of over $600 \mathrm{~m}$. The angle at the apex (in the horizontal plane) is $25-28^{\circ}$, indicating a great compression of the fold. 
The Petrovskoye deposit is located to the southwest of the Artemovskoye deposit. It is an appressed synclinal fold, facing south with a closure and being open to the north. The fold hinge plunges northeastward at a steep angle of $75-80^{\circ}$, flattening and undulating thereafter. The total length of the deposit is about $4 \mathrm{~km}$. The dip of limbs is westerly. The eastern limb dips at an angle of $45-75^{\circ}$, while the western limb slopes more steeply at $60-85^{\circ}$. The syncline is complicated by numerous discontinuous tectonic faults that break the deposit into blocks.

The iron ore sequence is represented by a single stratum. The greatest thickness of the iron ore stratum is determined in the fold closure, and then it very sharply decreases in the limbs. There is also heterogeneity in the structure of iron ore sequence and within the limbs.

The western limb is characterized by a fairly steep decline in the thickness of ore sequence from the closure to the northeast, with very minor variations. The eastern limb differs from the western one in the greater average thickness of the ferruginous bench, its sharper variations, and greater tectonic fragmentation.

The transcurrent tectonic faults split the eastern limb into a series of blocks, which shift relative to each other, therewith, the thickness of iron ore sequence also changing, both upward and downward.

\section{The structural peculiarities of iron ore deposits located in clo- sures of synclines}

The group of fields considered above, located in closures of synclines is characterized by a number of important common features, which should be paid attention to, given that this group of deposits is the most favorable for surface mining.

All mentioned deposits, as well as other deposits of similar type, are favorable by their structure for priority surface mining (taking into account, of course, their size and thickness of overlying sedimentary rocks). The deposits of greatest practical interest are those with the greatest ore sequence directly in the area of closing, i.e. the pit shell itself is located within the closure and insignificantly covers the fold limbs.

Structurally, the increase in horizontal and true thickness within a closure may be due to several reasons: 
$a$ - one of the important reasons is an intensively appressed fold, as a result of which we have a doubling of the horizontal thickness due to the convergence or contact of fold limbs (Skelevatskoye, Artemovskoye, Petrovskoye, etc.);

$b$ - an equally important factor is the gentle plunge of the hinge in the closing area. In this case, the ore formation has a large horizontal development area. Flattening of the ferruginous stratum occurrence within the deposit and a sharp plunge of the hinge outside of it is observed at a number of deposits (for example, Skelevatsky, partly Inguletsky, Zheltorechensky, etc.);

$c$ - increase in the horizontal thickness of ore sequence is caused by the presence of special structural conditions that contribute to the formation of cauldron-shaped basins in the area of fold closures (Inguletskoye and Gorishne-Plavninskoye deposits). These conditions are probably caused by block movements (subsidence) of the sedimentation basement, or by subsidence being similar to cauldron-forming processes in the final stages of the general volcanogenic cycle;

$d$ - as remarked by many researchers [7-10], there is a significant increase in the thickness of ore interlayers in the closing area of some iron ore deposits as compared to the thickness in the limbs. This may be due to the injection of mobile ore material during folding processes (layer-by-layer injection, features of metamorphism, etc.); a possible factor behind this process can also be considered as the features of primary sedimentation in conditions of inclined drift surfaces, where the closing area will be characterized by an increased inflow of material.

The mentioned structural features of deposits located in closures of synclines show that the presence of similar common structural features in the horizontal plane (general shape, character of the closure and limbs, etc.) is not always confirmed by the same deep structure. Particularly important is the angle of hinge plunge.

For example, with a very similar position in the structure of the Skelevatsky and Belanovsky (eastern) deposits, the different position of the hinge - in one case gentle, in the other - steep, determines their different commercial value. Another important feature should be considered the increased ore-bearing capacity of synclinal fold closures.

\section{Deposits in slightly disturbed synforms}

A representative of this subtype is the Gulyaypolskoye deposit, 
located in the Priazovskaya iron ore zone. It is believed that the deposit composes a large synform $(3 \times 9 \mathrm{~km})$ of oval shape, the axis of which is oriented in the northwestern direction.

he iron ore bed completely outlines the fold, undergoing discontinuities and compressions, as well as displacements along the systems of transcurrent fault dislocations. The horizontal thickness at the surface of the crystalline basement varies from $30-50 \mathrm{~m}$ in the central part of the fold up to $300-450 \mathrm{~m}$ in the northwestern and western parts. The dip of rock in the closures and on the limbs is steep - 75$80^{\circ}$, in some cases it is close to vertical. The lower boundary of ferruginous rock is $2.5-3 \mathrm{~km}$ in the northwestern part of the deposit, 1.5 $\mathrm{km}$ in the center, and $0.8-0.9 \mathrm{~km}$ in the southeastern part. Analyzing the distribution of ore sequence within the deposit, we can note that in the northwestern part, the most powerful thickness prevails (on average, over 100-120 m), and in the southeastern part, it is relatively small (30-70 m).

Typical volcanogenic complex of the host and interbedded with the iron ore stratum metamorphosed rocks, the nature of the fold itself, provide an opportunity to reasonably suggest that Gulyaypolskaya synform is also an eroded ancient (Proterozoic) caldera of collapse type.

\section{Deposits in anticlinal folds (Tarapakovsky type)}

Deposits of this type are much less common than deposits of other types. Anticlinal folds, depending on the conditions of formation, can be divided into two large groups - appressed (squeezed) and open. The appressed folds at the vertical position of the axial plane are characterized by steep pitches. In this case, if the limbs are composed by ore sequence, then in the central part of the fold in the closure it doubles due to their convergence, as well as due to additional folding. In some anticlines, there is a process of injecting ore material into the area of closing.

The open folds have gentle angles of limb inclination when the axial plane is vertical. In the central part, in the core, non-metallic strata often emerge. As a result, the configuration of the open pit may acquire a complex shape that inherits the ore sequence.

Deposits of this type may include the Severny and Yuzhny Tarapaki, the Inguletskaya anticline deposit (Pit of 2-bis AMKR).

The deposit of Inguletskaya anticline is the most studied. The 
hinge of Inguletskaya anticline plunges gently in a northerly direction at angles of $15-18^{\circ}$. The inclination of limbs is different. On the eastern limb it is $40-60^{\circ}$ to the east, south-east, on the western limb it is $60-80^{\circ}$ to vertical with a west, north-west dip.

The presence of different inclination of anticlinal fold beds, as well as the presence of discontinuities creates certain difficulties during mining operations, determining a different approach to the excavation of ore strata on the eastern and western pit wall. Differences in geological environment also result in varying degrees of their stability.

Deposits in anticlinal folds tend to change the qualitative composition and thickness of the ore sequence in different parts of the fold. Thus, in particular, the Tarapakovsky deposits are characterized by significant variability in the composition of the main ore bed $\mathrm{K}_{2}{ }^{4 \mathrm{f}}$. In contrast to neighboring synclinal-type deposits, the ore bed here has lower and more variable total iron and magnetic iron values. There are significant differences in the thickness of the eastern and western pit walls. The western strata (west dips) in TarapakovskoLikhmanovskaya anticline tend to decrease in total thickness.

A number of iron ore deposits of anticlinal character are caused by the formation of granitoid domes of various sizes. Metamorphic rocks, including ferruginous quartzite strata, encircle these domes completely or partially, being located in the limbs of these structures. This type of deposits includes Zapadno-Zelenorechenskoye, Kamchatka group of deposits, as well as a number of deposits and iron ore occurrences, intensely granitized, which are currently represented by separate, often spatially separated remnants, fringing granitoid massifs (domes). Such deposits and ore occurrences may include Chkalovskoye and Chervonoshakhtarskoye ore occurrences, Leninskoye, Orekhovskoye, Proletarskoye and Lozovatskoye deposits within the area of the Pravoberezhny Magnetic Anomalies, the Secretarskoye deposit at Pobuzhye, the Vostochny Novodanilovsk site within the OrekhovoPavlohradsky iron ore zone and others.

The most typical structures of these deposits may be observed on the example of the structure of the Zapadno-Zelenorechenskoye deposit and the group of Kamchatka deposits.

The Zapadno-Zelenorechenskoye deposit is located $4 \mathrm{~km}$ north of Artemovskoye one. Here there is a well-defined granitoid dome, consisting of plagioclase granites. It is bordered by a rock stratum 
containing a layer of silicate-magnetite ferruginous quartzite, forming a brachiatic anticlinal fold. The upper part of the fold is eroded and granitoids emerge on the surface of the crystalline basement. The thickness of the ore bed is 40-60 m. The occurrence of iron ore in the uneroded northwestern part of the dome is gentle to horizontal in the center and steeper on the limbs (from 30 to $60^{\circ}$ ). The eastern limb when dipping becomes steep, almost vertical up to reverse.

The hinge of the general anticline, the south-eastern reflection of which is the Zapadno-Zelenorechensky dome, gently plunges in a north-westerly direction. The upper apical part of the fold, composed by iron ore strata, is located within the crystalline basement surface along $800-900 \mathrm{~m}$, and further to the north-west it is overlapped by the overlying gneiss sequence.

\section{Monoclinal deposits (Saksagan type)}

Deposits of this type are the most common in quantitative terms. The banded, monoclinically dipping ore zones are most common in ore fields composed of iron-siliceous formations.

Linearly elongated zones composed of ferruginous quartzite are characteristic of all ore belts of the Ukrainian Shield: Belotserkovsko-Odessky, Krivorozhsko-Kremenchugsky, OrekhovoPavlogradsky, and Priazovsky.

Monoclinal deposits may be located in one ore field, being an extension of each other (Saksaganskoye, Annovskoye, Inguletskoye (Likhmanovskoye) ore fields), or articulated with deposits located in the area of synclinal fold closure (for example, GorishnePlavninskoye and Lavrikovskoye deposits). As noted above, we will refer to this type of deposits as a group of fields that have a synclinal overall structure, in which the fold closure is strongly plunged, and only monoclinically plunging limbs are located in the area of accessible mining.

Such deposits include: "Bolshaya Gleyevatka" (Pit No.1 of Central GOK), southern Annovskoye (Annovsky pit of SevGOK), northern Annovskoye deposit, Zheltyanskaya group - western and northeastern, Popelnastovskoye, Nikolaevskoye, Mlynkovskoye, Uspenovskoye, Lavrikovskoye, Eristovskoye, areas of Saksaganskoye ore field, Zelenovsky area of Likhmanovskaya (Inguletskaya) strip, etc.

For deposits of this type, the internal structure and thickness of 
the ore strata, the consistency of quality and thickness, both along the strike and down dip are of great importance.

Most monoclinal deposits belong to the second tectonotype, which is characterized by the intercalation of iron ore levels with shale ones. Therewith, their thickness plays a big role. The large thickness of non-metallic shale separating the iron ore strata makes it necessary to mine selectively each ore bed. The relatively low thickness (usually less than $10 \mathrm{~m}$ ) of non-metallic beds is mined together with ore levels, reducing the overall quality. In this regard, monoclinically built iron ore deposits are divided by the quality of individual ore beds into one-, two-, three-, and four-layer, as well as multi-layer deposits, which contain a greater number of layers.

The one-layer ore formation is characterized by a single ore layer, which may include one or more technological varieties, as well as minor in thickness (less than $10 \mathrm{~m}$ ) non-metallic layers, veins or lenticular inclusions.

The two-layer ore formation consists of two sub-parallel layers of ferruginous quartzite, which are separated by a non-metallic formation of similar thickness or greater than the thickness of a single ore layer, usually exceeding $10 \mathrm{~m}$. Formations may be of equal thickness and technological characteristics, or slightly different. With large differences in thickness and quality, joint development may be partial or concentrated on a single layer only.

Accordingly, the three-layer productive formation consists of three equivalent or slightly different in thickness ore beds, separated by two non-metallic (usually shale or gneiss) strata with thickness exceeding $10 \mathrm{~m}$.

The four-layer iron ore formation consists of four beds of ferruginous quartzite separated by three strata of non-metallic rocks. It is often noted that two or three layers converge, and sometimes merge to form a single stratum, when the ore sequence is four-layered.

The multi-layer iron ore sequence consists of many (more than 4) strata separated by non-metallic beds.

Often, such strata are represented by relatively thin iron ore layers, also separated by thin non-metallic beds.

Such zones are generally difficult to mine selectively and often the total thickness of the ore strata does not meet the requirements of the conditions. In such cases, individual sections of the ore layer that 
meet the condition requirements are selected for further mining.

When assessing monoclinal deposits, the length of iron ore layers, their total thickness and thickness of individual layers, both along the strike and down dip, their stability within the deposit, as well as parameters characterizing the quality of raw materials play a great role.

The length of the ore beds determines the total reserves of raw materials.

A number of deposits with monoclinal occurrence are characterized by the sustained extent of the main ore strata. However, there are also fields where, in the presence of one or two stable main strata, there are phenomena of wedging in neighboring strata, cutting by tectonic faults, combining two strata into one, and also phenomena of splitting of one thick bed into several thin beds.

The thickness of ore sequence determines the main parameters of the open pit; the presence of two or more sub-parallel ore strata affects the configuration of the bottom and walls of the open pit.

Monoclinal ore beds in deposits of this type usually dip steeply, almost vertically. This allows for a clearer distinction when mining the conditioned, substandard and non-metallic rock strata over long distances along the strike.

The stability of the thickness and quality of ore raw material along the strike and dip may be disturbed by the presence of folding (vertical flexures), as well as by diagonal and transverse tectonic faults. Folded deformations in the form of vertical flexures (a vertical hinge, the Saksaganskoye ore field) and less frequently horizontal flexures (horizontal fold hinge, the Annovskoye ore field) are noted in deposits of this type. The amplitude of these deformations plays a major role. Insignificant amplitudes (not exceeding 0.5 thickness of the ore sequence) have relatively little effect on the overall mining plan. Large amplitudes of flexures have a significant impact on the configuration of the open pit and on technological solutions for the location of openings (the location of pit roads, crushing and reloading points, conveyors) [11]. The presence of flexural bends also affects the quality of ore raw material. Within these bends, an increased degree of oxidation of ferruginous quartzite is noted, up to the oxidized rich iron ores, and the physical and mechanical properties change.

Discontinuous tectonic faults also lead either to an increase or to a reduction in the thickness of ore strata. This phenomenon is charac- 
teristic of diagonal shear deformation, both in plan and in section (Pit 1 of CGOK).

Transverse discontinuous tectonic faults also disturb the occurrence of the ore sequence, shifting it in one or another direction relative to the middle strike line. The magnitude of these shifts is also very influential on the formation of the open pit, if it reaches values greater than 0.5 thickness of the ore strata.

Qualitative indicators and the complex of physical and mechanical properties in the zone of the influence of tectonic faults behave differently. In a number of faults and their zone of influence, there is a very sharp difference of these parameters from the main thickness. This is due to the presence of numerous fault seams, increased fracturing of the adjacent rocks, the presence of superimposed hydrothermal and hypergenic processes that significantly change the original rocks. The spatial parameters of the zone of influence caused by tectonic movements along faults and superimposed processes are often very difficult to estimate, due to their great unconformity along the fault. At the same time, there are a number of discontinuous tectonic faults (most often transverse) along the zones of which, despite significant displacement of the strata, there are almost no changes in the surrounding rocks (Annovsky open pit). The zone itself is represented in this case by a narrow strip (first $\mathrm{cm}$, tens of $\mathrm{cm}$ ), grinded and cemented by the surrounding rock.

\section{Consideration of structural types of iron ore deposits in the design of open pits}

Typification of iron ore deposits by structural features is extremely important when designing the mining companies. It allows us to take into account the features of the geological structure as early as the design stage, to provide for the development of mining operations at different depths, to anticipate the required set of mining and geological researches and capital works. On the other hand, the typification of deposits will enable us to take advantage of the experience in development of similar types of previously stripped or exhausted deposits.

In view of the above, much attention should be paid to the issues as follows: a) types of deposits, their sizes and reserves of raw materials; b) type of the deposit and the projected configuration of the open pit in plan and section, the capacity of proven reserves to be 
extracted; c) the stability of pit walls when mining deposits of different types; d) opportunities for development of small deposits and deposits with variable overburden thickness; e) clarification of the relationship of structural types of deposits and their degree of profitability.

a) types of deposits and proven reserves

The above data on the typification of deposits makes it possible to highlight the parameters and characteristics of deposits, which should be considered when designing and developing by the surface mining method. One of the key indicators is the size of proven reserves.

The most favorable for surface mining is Skelevatsky (synclinal) type of deposits, characterized by large reserves and a synclinal structure being optimum for mining: the core and limbs of the syncline are ore sequence. The structure of the deposit contributes to the full development of reserves, as the parameters of the open pit in the area and in the section coincide with the ore sequence.

For Tarapakovsky (anticlinal) type deposits, the most favorable for mining is the closing part of the fold. Plunging limbs may only be of interest up to a certain depth. The reserves in the limbs cannot be fully extracted by the surface mining method.

Also favorable for surface mining is Pervomaisky (concentrated block) type of deposit, within which the ore body, although broken into separate blocks, but in general the pit shell is located within the ore body, despite the shifts of ore blocks.

Among the deposits of Saksagansky (monoclinal) type, only deposits with large reserves, which have a large horizontal thickness and high quality of ore strata, being capable of overlapping the costs of excavation, haulage and storage of waste and host waste rocks are favorable for surface mining.

Deposits with a complex structure and low thickness of ore beds are classified as problematic for surface mining. The decision on the possibility of surface mining is made on the basis of simulation of the optimum boundaries and mode of mining operations.

b) types of deposits and configuration of open pits in plan and section

The structure of the deposit determines possible degree of completeness of its development. The considered types of iron ore depos- 
its allow us mainly to determine the position of the open pit in plan and in section. However, if for Skelevatsky type the issue of the spatial position of the open pit within the field does not cause special difficulties, for other types of this issue is very relevant. For Tarapakovsky and Shimanovsky types of deposits, not only the position of the open pit in plan, but especially the vertical section of the pit is important. The uneven thickness and quality of the western and eastern limbs of the anticline (Severny Tarapak and Yuzhny Tarapak deposits) makes us lean toward the idea of developing an asymmetric cross-sectional profile of the open pit. With the progress in mining operations, the fold limbs will be developed first, leaving for a later period the central, elevated part of the deposit, represented by poorer varieties of ferruginous quartzite and a thicker mass of the shale level (shale 3-4).

A complex configuration, both in plan and cross section, will have pits opening anticlinal deposits, being similar in structure to Zapadno-Zelenorechenskoye or Kamchatka deposits. Here, the ore sequence is thickest in the periclinal sections, where the hinge of the anticline slopes downward, forming gentle synclinal bends. The structure of these bends is very complex; it is identical to the foldedblock deposits, where both folds and blocks offset one another are noted. If it is possible to develop the ore stratum on the limbs, the open pit will bifurcate, inheriting their configuration.

Features of the geological structure of deposits of Pervomaisky type should also be taken into account in the design of open pits. Large shifts in the horizontal and vertical planes make adjustments to the optimum pit wall design. It is necessary to take into account the position, directions of shift and rotation angles of the structural blocks of the deposit when planning the mining operations.

In the deposits of Saksagansky type, the open pits extend in the direction of ore stratum strike. Here, folded flexure-type dislocations with horizontal and vertical hinges, as well as thrust and strike-slip faults will play a major role. The presence of such dislocations leads to a change in the configuration of the open pit in plan and in section (Annovsky open pit).

The increase and decrease in the amount of extracted iron ore raw materials as compared with the proven reserves may be explained by technological (dilution and losses) and geological (rare exploration 
network) factors, as well as the uniqueness of the deposit structure, which cannot be accounted for by the existing methods of exploration. The presence of mesofaulting, low- and medium-amplitude block dislocations introduces certain corrections to the estimation of total deposit reserves. These corrections may be taken into account when comparing geological exploration data and actual iron ore production volumes with a correction for a certain deposit type. No such work has been done. However, given the existing data, it can be noted that these divergences will increase from simple structures of deposits (Skelevatsky type) to more complex ones (folded-block type of deposits).

c) Stability of pit walls when mining the different types of deposits

The degree of pit wall stability is greatly influenced by the dip angles of their host rocks, as well as the presence and spatial location of major faults.

The direction of the dip in synclinal folds is oriented toward the center. A dip of 60-75 is considered most favorable for good pit wall stability. Such a dip corresponds to the parameters of the bench slopes. The stability of pit walls is sufficient, even in the presence of interbedded tectonic faults. At sub-vertical dip (80-90) there is also a fairly high stability of pit walls.

More gentle dip (30-50), which does not coincide with the technological rules determining the value of the bench slope (70-75), is unfavorable for the pit wall stability. A very gentle occurrence ( 0$20^{\circ}$ ) also creates a more reliable stability.

More favorable conditions for pit wall stability are created by simple anticlinal folds, stipulating the reverse dip of rocks, which provide sufficient stability at various angles of rock dipping.

Similar to the dip of rocks, the pit wall stability is affected by tectonic faults, causing fractured unstable zones. Water often seeps through them, creating additional instability. Complicating mesofaulting and shallow blockiness create additional factors that weaken the pit wall stability.

For deposits of complex structure, where the location of rock dips and faults is not reliable, the pit wall stability requires constant attention during the entire deposit development process.

d) peculiarities of development of small deposits with large overburden thickness 
Along with large deposits, the raw material base of ferrous metallurgy in Ukraine is represented by a large group of small deposits, much of which can be developed by surface mining method. There are such deposits in the Pobuzhye, in the Pravoberezhny area, in the Priazoviye. Small open pits will ensure the extraction of high quality ore in a short time with relatively small capital expenditures. As an example, in the past, iron ore mining in the Krivbass began with the development of small deposits.

With a large thickness of overburden and the use of a set of mining equipment being standard for the iron ore open pits in Ukraine (electric rope shovels with a 10-12 cub m bucket and 130 ton dump trucks), involving in the development of small deposits will require a large amount of capital and stripping operations. This problem manifested itself during the commissioning of deposits such as Artemovskoye and Petrovskoye (Pravoberezhny Magnetic Anomalies, the Kirovograd region), where, along with loose overlying rocks, the ore body is overlain by Precambrian rocks represented by shale.

Since the share of small deposits is large, the justification and development of new methods of opening up and development of such fields are an urgent task [11]. It is possible to reduce the volume of capital and stripping operations by means of dump trucks, which require a smaller width of transport berms, and overcoming large longitudinal slopes (up to 15-20 degrees). The use of skip hoists and inclined conveyors, including those located in underground mine workings, may be effective. The combined surface-underground method of deposit development will also be effective. At the first stage, the open pit mines the most favorable part of the deposit for surface mining (the closing part of the syncline, the bed section with the maximum thickness, etc.). At the second stage, adits are used to open the reserves of the deposit located outside the pit. Transportation of ore extracted by underground mining method from the adits to the day surface is carried out by haulage berms on the pit wall.

e) the role of deposit structure in the degree of profitability of mining.

In [8] it is noted that the structure of the deposit affects the technical and economic performance of the open pit and its profitability. A comparative analysis of mining and geological conditions and technical and economic indicators of deposits under operation, 
showed [8] the dependence of the efficiency of field development on its geometric parameters and reserves. Mining efficiency is affected by the shape of the ore body, its thickness, and the thickness of overburden. As the thickness of the ore body increases, the operational stripping ratio decreases and the maximum output capacity of the open pit increases; as the thickness of overburden increases, the operational stripping ratio and the amount of mining and capital operations increase.

\section{Statistical and geometric analysis of deposits}

Deposits of synclinal and anticlinal types are characterized by the set of parameters as follows: an angle of the hinge plunge; number of ferruginous levels; total thickness of ferruginous levels in each fold limb; a dip angle of fold limbs; an azimuth of fold limbs; a length of fold limbs; reserves of ferruginous quartzite; thickness of sedimentary mantle; average content of iron in ore and in concentrate. Stratified deposits are characterized by the set of parameters as follows: an azimuth of the stratum strike; stratum dip angle; thickness and length of each stratum; total thickness of the strata; total thickness of waste rock separating the mineral strata; reserves of ferruginous quartzite; thickness of the sedimentary mantle; average iron content in ore and in concentrate. The selected indicators allow geometrically describing the simplified productive strata of promising deposits.

The deposits de facto are much more complex than the simplified scheme used to represent the field through its main parameters. Various sources of information (monographs, articles, dissertations, research reports, exploration reports) were used to collect deposit parameters. The simplified, skeleton models of deposits were created based on the selected and averaged parameters. Ore reserves calculated by simplified models were compared with the deposit reserves given in the geological literature. In case of a significant discrepancy, the deposit parameters were rechecked and corrected on the basis of cartographic materials. For a number of deposits, inferred resources (usually category $P_{1}$ ) are used as reserve data.

In the process of collecting information on iron ore deposits in Ukraine, 133 deposits were analyzed (including Krivorozhsky iron ore district and Pravoberezhny anomalies - 58, Kremenchugsky district - 27, Pridneprovsky - 11, Belozersko-Orekhovsky - 20, Odessko-Belotserkovsky - 5, Priazovsky - 12). 42 deposits were selected in 
order to further study and generalize the parameters of iron ore deposits that are promising in terms of surface mining. The main criterion for the selection of deposits was the thickness of the sedimentary mantle of no more than $100 \mathrm{~m}$.

The main classification feature is the structure and morphology of a part of the ore sequence in the depth interval being available for surface mining (up to 500-700 m). For example, a synclinal field with a deep hinge and a low thickness (10-20 m) of one of the limbs was considered as a stratified deposit. The parameters characterizing its structure in terms of the possibility of surface mining were specified for each deposit.

A number of deposits (Orekhovskoye, Proletarskoye, Krasnofedorovskoye, Zheltyanskoye, Nikolaevskoye, Severo-Tersianskoye, Vasinovskoye, Novoukrainskoye, Kuksungurskoye, Korsakskoye) are characterized by a very complex structure that makes it impossible to characterize them as a whole. Moreover, individual sections of the deposits are located from each other at a considerable distance, measured in hundreds of meters, which allows us to conclude that until a certain stage of development or even until its completion, these ore bodies will be developed by separate open pits. Each of these deposits was divided into separate sections and these sections were subsequently treated as separate productive strata.

Thus, on the basis of 42 iron ore deposits, 60 separate productive strata were identified, which were analyzed and further considered as separate deposits. The total reserve of ferruginous quartzite in the deposits selected for analysis is more than 20 billion tons.

When analyzing the scope of deposits as a whole, we proceeded from the categories determined by the classification of the iron ore mineral resource base in the USSR according to the size of deposits. In accordance with this, the totality of deposits by reserves was conditionally divided into 6 categories. Unique deposits are characterized by ore reserves over $3000 \mathrm{mln}$ tons, rather large (RL) 1500-3000 mln tons, very large (VL) 750-1500 mln tons, large (L) 350-750 mln tons, medium (M) 50-350 mln tons and small (S) 5-50 mln tons.

Analysis of the collected information shows that 50 deposits are classified in terms of surface mining as stratified (S), 5 - as synclinal (S) and 5 - as anticlinal (A) fields.

Fig. 1-2 show the distribution of reserves and the number of iron 
ore deposits by size and morphological structure. The stratified deposits are associated with $82.5 \%$ of ferruginous quartzite reserves and $83.3 \%$ of the total number of deposits, with synclinal deposits $3.3 \%$ of reserves and $8.3 \%$ of the deposits, with anticlinal - about $14 \%$ of the balance reserves and $8.3 \%$ of the number of deposits. Thus, the existing opinion about the predominance of stratified fields among iron ore deposits being suitable for surface mining is confirmed.

$40 \%$ of reserves are concentrated in very large fields, which represent $13 \%$ of the total number of deposits. They are followed by large and medium-sized fields, which represent 26.1 and 22.6 percent of reserves, respectively, and 21.7 and 53.3 percent of the number of deposits. Small fields account for less than $1.5 \%$ of total reserves and $10 \%$ of total number. In turn, rather large fields account for $10.4 \%$ of reserves and $1.7 \%$ of the number of deposits.

Very large stratified fields represent $30.3 \%$ of total reserves, large ones $-22.0 \%$, medium ones $-18.8 \%$, rather large stratified fields $10.4 \%$.

The participation of classic synclinal deposits in the balance of reserves is insignificant - about 3\%, while anticlinal deposits represent $13 \%$ of reserves. The shares of synclinal and anticlinal deposits in the total number of deposits are approximately equal (about $8 \%$ ). There are no synclinal deposits with reserves over $350 \mathrm{mln}$ tons. Anticlinal deposits represent $10 \%$ of very large deposits and about $5 \%$ of large deposits (Fig. 1a). Among the small deposits, the share of anticlinal deposits in the distribution by reserves and number of deposits is insignificant.

The iron ore deposits is analyzed by the length of ore bodies (Fig. $3,4)$ with distribution into five categories: up to $1000 \mathrm{~m}, 1000-2000$ $\mathrm{m}, 2000-3000 \mathrm{~m}, 3000-4000 \mathrm{~m}$ and $4000-5000 \mathrm{~m} .37 \%$ of reserves and $43 \%$ of deposits of their total number are characterized by the length of ore bodies from 1000 to $2000 \mathrm{~m} .25 \%$ of reserves are associated with the length of ore bodies along the strike of over $3000 \mathrm{~m}$. The length of ore bodies less than $1000 \mathrm{~m}$ is characterized by $8 \%$ of reserves and $28 \%$ of the total number of deposits. The range from 2000 to $3000 \mathrm{~m}$ is representative $-31 \%$ of the reserves and $17 \%$ of the number of deposits.

The iron ore deposits is analyzed by the total horizontal thickness 
of ore bodies (Fig. 5, 6) with distribution into seven categories: up to 50m, 50-100 m, 100-150 m, 150-200 m, 200-300 m, 300-500 m and over $500 \mathrm{~m}$. More than $50 \%$ of the total deposits reserves (Fig. 5) are represented by ore bodies with horizontal thickness over $200 \mathrm{~m}$ (Fig. $5 \mathrm{~b}$ ): $30 \%$ of reserves are characterized by horizontal thickness of $200-300 \mathrm{~m}, 17 \%$ - 300-500 m and 6\% - over $500 \mathrm{~m}$. Over $50 \%$ of the total number of deposits (Fig. 6) have a horizontal thickness of less than $100 \mathrm{~m}, 18 \%$ more than $200 \mathrm{~m}$.

In the process of designing the surface mining a number of strategic tasks are solved: determining the boundaries of the open pit, the choice and justification of opening-up methods and development system, the choice of direction of mining development in the open pit area and provision of ore, overburden and rock output capacities.

In projects for the deposit development, it is obligatory to calculate the maximum possible production capacity in terms of mining and technical factors and to analyze the dynamics of its development from the beginning up to the final open pit. The production capacity determined in this way is the upper limit of production capacity in its search area.
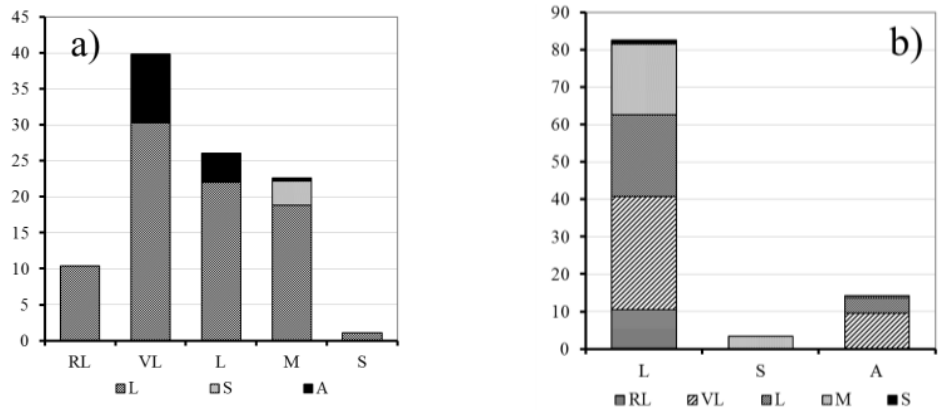

Fig. 1. Distribution of reserves of iron ore deposits by grain size categories (a) and by deposit morphology (b) 

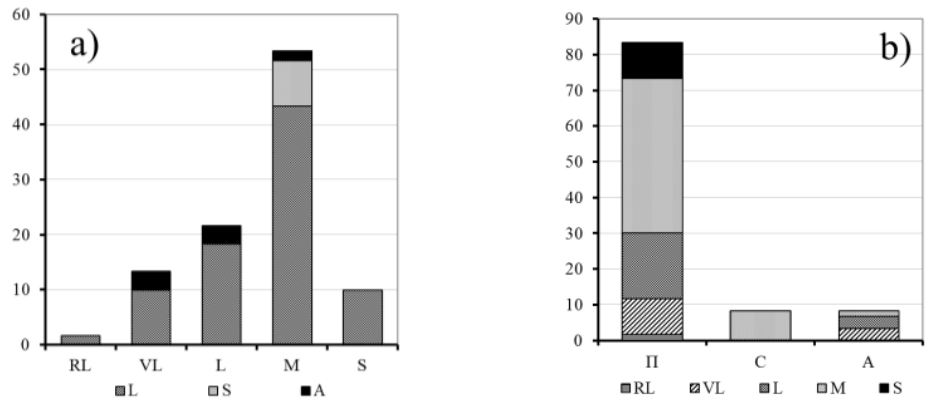

Fig. 2. Distribution of the number of iron ore deposits by grain-size categories (a) and by deposit morphology (b)
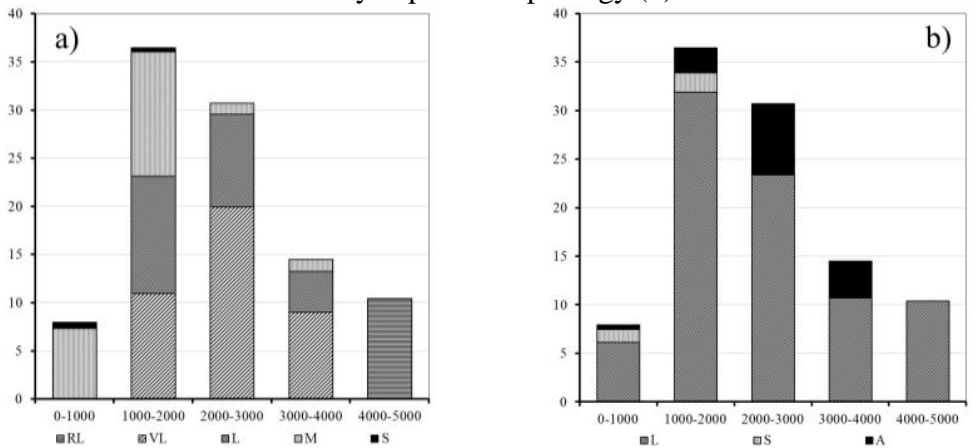

Fig. 3. Distribution of reserves of iron ore deposits of different size (a) and different morphology (b) depending on the extent of ore bodies along the strike
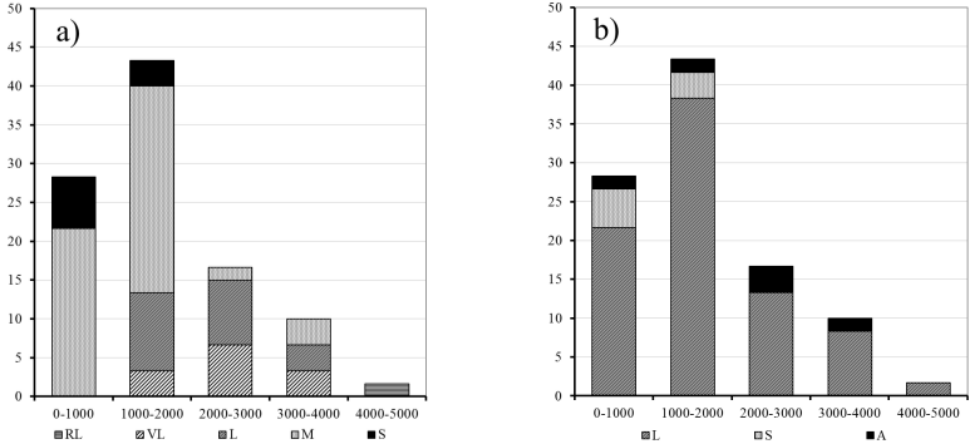

Fig. 4. Distribution of the number of iron ore deposits of different size (a) and different morphology (b) depending on the extent of ore bodies along the strike 

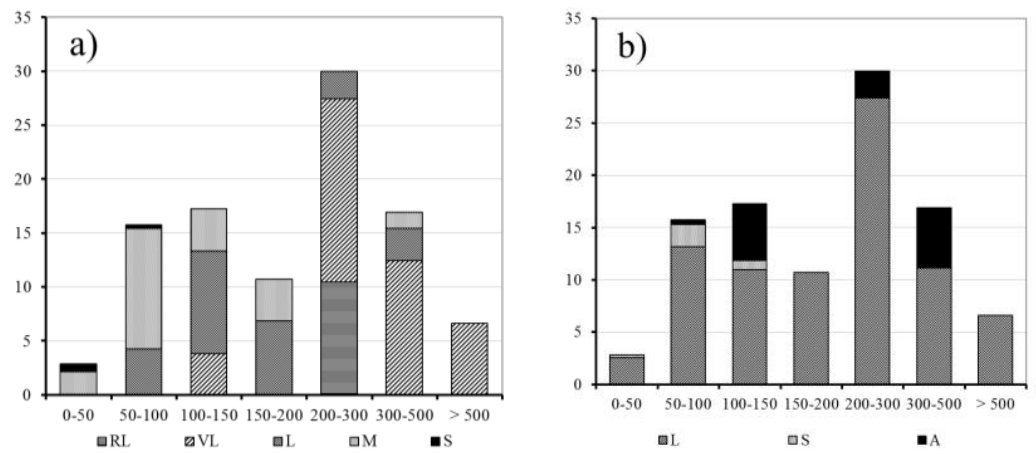

Fig. 5. Distribution of reserves of iron ore deposits of different size (a) and different morphology (b) depending on the horizontal thickness of ore bodies
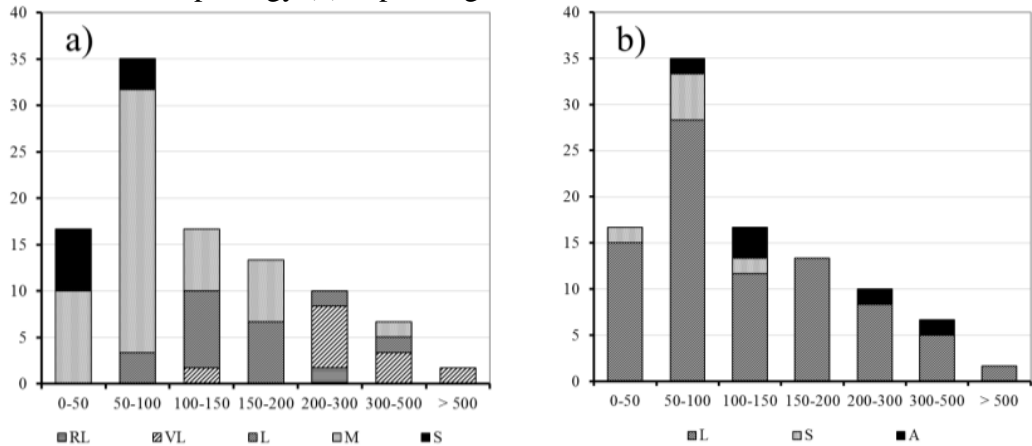

Fig. 6. Distribution of the number of iron ore deposits of different size (a) and different morphology (b) depending on the horizontal thickness of ore bodies

According to the standards of technological design, the possible ore production is determined by the formula

$$
A_{\mathrm{p}}=h_{\Gamma} S_{P} \rho \frac{1-r}{1-v}, \mathrm{t},
$$

where $h_{\Gamma}$ is the rate of vertical mining, m/year; $S_{\mathrm{P}}$ - ore body area, within which the mining operations deepen, $\mathrm{m}^{2} ; \rho$ - ore density in the subsurface, $\mathrm{t} / \mathrm{m}^{3} ; r$ - operational ore losses, unit fractions; $v-$ weight dilution factor, unit fractions.

In specific geological and technical conditions, the determining parameter for calculating the possible production capacity of the open pit is an indicator of the intensity of the development of steeply dipping deposits - the rate of vertical mining. In design practice, at the stage of feasibility studies, as well as in approximate calculations, 
the rate of deepening the open pit is taken by analogy. At open pits that use rail transport, the annual deepening of mining operations is on average 6-10 m/year, and with road transport 10-15 m/year.

Thus, the technically possible production capacity of the open pit is a function of the ore zone area, which in first approximation is equal to the product of the length of the ore body by the horizontal thickness. Using the collected information about iron ore deposits, you can make a preliminary prediction about the possible production capacity of the open pit and the degree of favorability of mining and geological environment. The main factors influencing the degree of the deposit favorability for surface mining are the thickness of overlying rocks and the total horizontal thickness of ore bodies. It is known that with an equal ore body area, more favorable mining conditions will be characterized by an open pit, which develops the ore body of greater horizontal thickness and shorter length along the strike.

The distribution of ferruginous quartzite reserves depending on the total thickness and strike of ore bodies for promising and operating deposits is shown in Fig. 7. The figure also shows graphs (hyperboles) defining the set of values of ore body thickness and extent along the strike, the product of which is equal to the area of 5,10,15, 20,30,40,50 and $100 \mathrm{ha}$. Assuming the rate of deepening of a conventional open pit to be equal to $7.5 \mathrm{~m} /$ year, we obtain that the ore body area, being equal to $100 \times 100 \mathrm{~m}$ ( $1 \mathrm{ha})$, provides production of about $0.25 \mathrm{mln}$ tons/year of ferruginous quartzite. The obtained value is overestimated, let's take it as the maximum possible production capacity. Accordingly, the ore area of 5 ha provides annual production of $1.25 \mathrm{mln} \mathrm{t}, 10$ ha $-2.5 \mathrm{mln} \mathrm{t}, 20 \mathrm{ha}-5 \mathrm{mln} \mathrm{t}$ and $100 \mathrm{ha}-$ $25 \mathrm{mln}$ t. Focusing on the position of promising deposits relative to the hyperbolas, which determine the possible production capacity of the open pit at the corresponding values of thickness and strike, we can estimate the industrial potential of the deposits.

Analysis of the position on the graph of deposits under operation correlates with the known data on mining and geological conditions in the pits that develop them.

Over $80 \%$ of reserves are characterized by deposits with a level of maximum possible production capacity exceeding $5 \mathrm{mln}$ t/year. These are mostly fields with reserves of more than $350 \mathrm{mln} \mathrm{t}$ (40\% of the total 
number of analyzed deposits). About $36 \%$ of the total number of deposits is characterized by a possible production capacity of less than $2.5 \mathrm{mln}$ t/year, and $7 \%$ of reserves are associated with these fields.

The influence of the thickness and character of occurrence of the ore body on the main technical and economic indicators of deposit development was investigated on the example of a stratified-type deposit. For this purpose, calculations were made of the volume of extracted ore and overburden removed from the pit for different options of the final pit, developing a deposit with given parameters. A mining and geometric analysis of a typical series of deposits characterized by the general parameter - the strike of $2000 \mathrm{~m}$ and a variable parameter - the horizontal thickness of the ore body from $50 \mathrm{~m}$ to $250 \mathrm{~m}$ were performed for the stratified type. The depth of occurrence of the ore body is $500 \mathrm{~m}$, the thickness of the overlying rocks is $0 \mathrm{~m}$. The obtained dependences of the overburden volumes from the ore reserves in the open pit are shown in Fig. 8 (dashed lines). Analysis of the calculation results shows that the horizontal thickness of the ore body has a decisive influence on the technical and economic indicators of development.

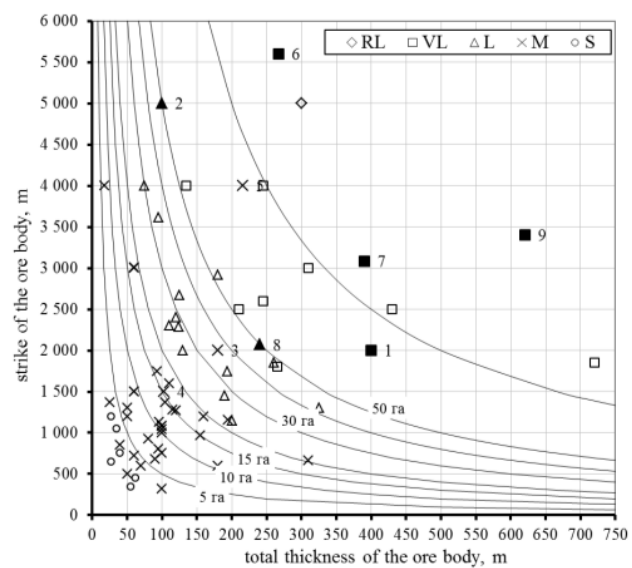

a) distribution of deposits by reserves 


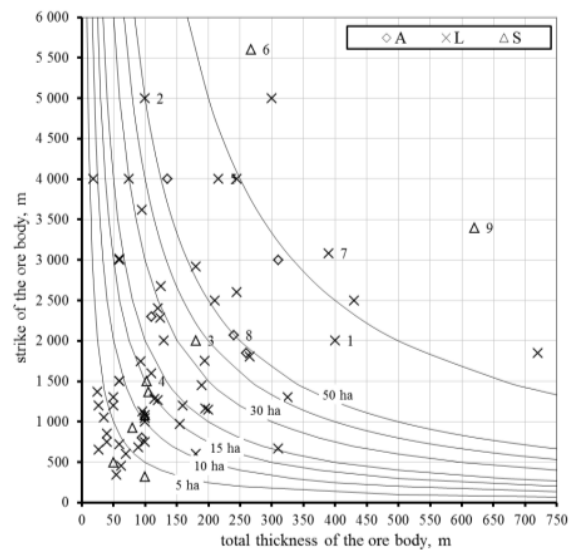

b) distribution of deposits by morphology

Fig. 7. Distribution of deposits depending on the total thickness and strike of ore bodies for promising and operating deposits (1 - Pervomaiskoye, 2 -

Annovskoye, 3 - Petrovskoye, 4 - Artemovskoye, 5 - Bolshaya Gleevatka, 6 Skelevatskoye, 7-Valyavkinskoye, 8-Novovokrivorozhskoye, 9 - Inguletskoye)

In order to analyze the technical and economic indicators of surface mining, the lines of equal specific operating costs $(\$ / t)$ were plotted in Fig. 8. The lines of equal specific costs connect the points characterizing the volumes of ore and overburden in the final pit shell, developing deposits of the type series, where the specific operating costs became equal to the specified level. In Fig. 8, the lines of specific operating costs in the range of possible values are plotted in increments of $\$ 1 / \mathrm{t}$. The lines of equal costs are represented by a bundle of straight lines, the greater the slope of which is the higher the specific operating costs of the pit in question. The straight line on the graph of increasing volumes corresponds to the same value of the stripping ratio.

Analysis of a number of stratified deposits with the ore body thickness varying from $50 \mathrm{~m}$ to $250 \mathrm{~m}$ shows that as the thickness of the ore body increases, the technical and economic performance of open pit development improves. This allows us to conclude that, along with the thickness of the ore body, the ratio of the horizontal area of the ore body to its perimeter is an important parameter that affects the technical and economic performance. The greater this value, the more favorable conditions for development of the deposit we have. 


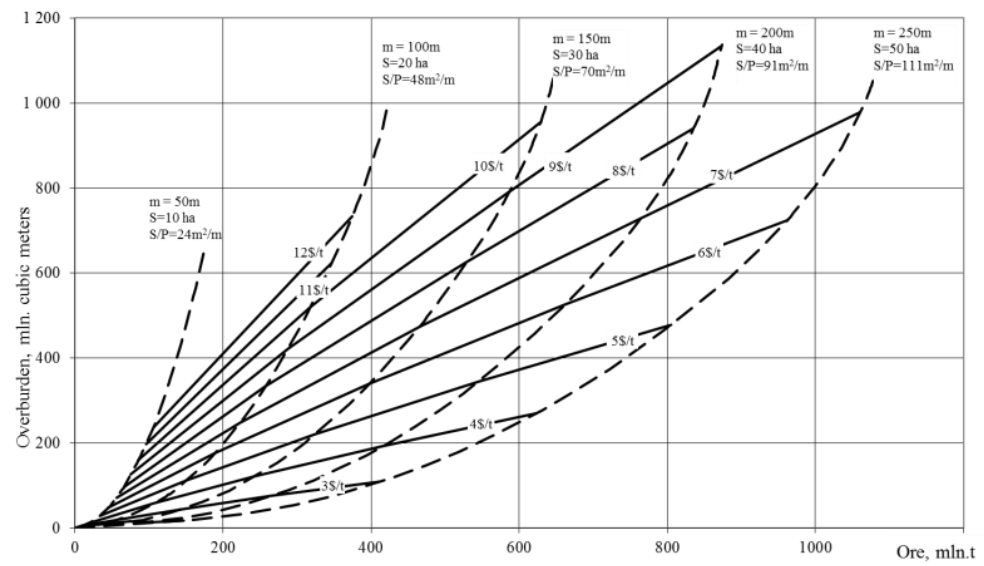

Fig. 8. Dependences of overburden volumes on ore reserves within the pit shells developing stratified deposits with different horizontal thickness of the ore body

Conclusions and directions for further research. It was found that the stratified deposits are $82.5 \%$ of reserves of ferruginous quartzite and $83.3 \%$ of the total number of deposits, synclinal deposits $-3.3 \%$ of reserves and $8.3 \%$ of deposits, anticlinal - about $14 \%$ of the balance reserves and $8.3 \%$ of the number of deposits. $50 \%$ of ferruginous quartzite reserves are represented by deposits with a horizontal thickness of over $200 \mathrm{~m}$ (18\% of the total number of deposits). The performed mining and geometric analysis allows us to determine as a priority the further development of the surface mining theory of stratified steeply dipping deposits.

Typification and parameterization of structural types of iron ore deposits systematizes approaches to the assessment of different types of deposits, which will improve the efficiency of evaluation and preproject work on the development of new deposits. A systematic approach to the analysis of iron ore deposits will allow for a more detailed assessment of proven reserves of iron ore raw materials, to determine rational parameters of open pits and mining technology, to determine the basic principles of rational development of small and medium-sized deposits.

In further studies, it is necessary to analyze the impact of the thickness and nature of the ore body occurrence on the mining tech- 
nology, the method of opening and the main technical and economic indicators of surface mining.

\section{References}

1. Rzhevskiy V.V. (1975). Tekhnologiya i kompleksnaya mekhanizatsiya otkrytykh gornykh rabot [Technology and complex mechanization of open pit mining]. Moscow: Nedra [in Russian].

2. Sheshko Ye.F.(1951). Otkrytaya razrabotka mestorozhdeniy poleznykh iskopayemykh [Open pit mining of mineral deposits].

Moscow: Ugletechizdat [in Russian].

3. Arsent'yev A.I.(1981). Vskrytiye i sistemy razrabotki kar'yernykh poley [Opening and quarry field development systems]. Moscow: Nedra [in Russian].

4. Drizhenko A.Yu., Martynenko V.P., Simonenko V.I.(1994). Vskrytiye glubokikh gorizontov kar'yerov [Opening of deep horizons of open pit mines]. Moscow: Nedra [in Russian].

5. Martynenko V.P.(1999). Nauchnoye obosnovaniye i razrabotka ekologicheski oriyentirovannykh tekhnologiy gornykh rabot na zhelezorudnykh gorno-obogatitel'nykh kombinatakh [Scientific substantiation and development of environmentally oriented mining technologies at iron ore mining and processing plants]. Thesis of Doctor of Technical Sciences. Dnepropetrovsk [in Russian].

6. Gross G.A.(1969). Geologo-ekonomicheskaya otsenka zhelezorudnykh mestorozhdeniy [Geological and economic assessment of iron ore deposits]. Moscow: Mir [in Russian].

7. Verigin M.I., Epatko Yu.M., Orlov V.P. (1990). Zhelezisto-kremnistyye formatsii dokembriya yevropeyskoy chasti SSSR. Prognoznaya otsenka zhelezorudnykh mestorozhdeniy [Ferro-siliceous formations of the Precambrian of the European part of the USSR. Predictive assessment of iron ore deposits]. Kiev: Naukova dumka [in Russian].

8. Kulish E.A., Plotnikov A.V. (2005). Geologicheskiye faktory ekonomicheskoy tsennosti zhelezorudnykh mestorozhdeniy

[Geological factors of the economic value of iron ore deposits]. Kiev: Logos [in Russian].

9. Belevtsev Ya.N., Epatko Yu.M., Verigin M.I. (1981). Zhelezorudnyye mestorozhdeniya dokembriya Ukrainy i ikh prognoznaya otsenka [Precambrian iron ore deposits of Ukraine and their predictive assessment]. Kiev: Naukova dumka [in Russian].

10. Semenenko N.P. (1959). Geologiya zhelezisto-kremnistykh formatsiy Ukrainy [Geology of ferruginous-siliceous formations of Ukraine]. Kiev: Academy of Sciences of the Ukrainian SSR [in Russian].

11. Vilkul Yu., Slobodyanyuk V., Maximov I. (2021). Optimisation of location and performance parameters for the crushing and transfer stations in the deep open pit mines. Sustainable Extraction and Processing of Raw Materials Journal. №2. 